\title{
EXPLORING THE CONNECTIVITY OF ECOLOGICAL CORRIDORS BETWEEN LOW ELEVATION MOUNTAINS AND PINGTUNG LINHOUSILIN FOREST PARK OF TAIWAN BY LEAST-COST PATH METHOD
}

\author{
Y. L. Huang ${ }^{\text {a }}$ H. F. Liu' ${ }^{\text {b J. C. Chen }}{ }^{\text {b }}$ C. T. Chen ${ }^{\text {b, } *}$ \\ ${ }^{a}$ Graduate Institute of Bioresources, National Pingtung University of Science and Technology. 91201 No.1, Shuehfu Rd., Neipu, \\ Pingtung, Taiwan - goodrinoa93@gmail.com \\ ${ }^{\mathrm{b}}$ Department of Forestry, National Pingtung University of Science and Technology. No.1, Shuehfu Rd., Neipu, Pingtung, 91201
}

Taiwan.

Commission VIII, WG VIII/7

KEY WORDS: Linhousilin Forest Park, Landscape ecology, Least-cost path, Gravity model

\begin{abstract}
:
The primary purpose of this study was explored the variation of landscape process and its impact on the possibility of ecological corridors on Pingtung Linhousilin Forest Park. Developing the landscape change process in year 2002, 2005, 2012 and 2014 via the land-use definition of IPCC (forest land, cropland, grassland, wetlands, settlements and other land). In the landscape structure analysis, the cropland was gradually changed to forest land in this area. Moreover, the variation of gravity model showed that the interaction between Linhousilin Forest Park and low elevation mountains were gradually increased which means the function of ecological corridors has increased.
\end{abstract}

\section{INSTRUCTIONS}

The environment are affecting by population increasing, human activity, economy development, which lead to deteriorate on global ecosystem, and habitats quality even the structure, function and diversity on global ecosystem. Long-tern ecological research station provides the environmental changing data for monitoring the ecosystem dynamic, ecological phonemes and process. On that, the main issue should be focused on determining the magnitude and impact of environmental change mechanism. The landscape is a macro system provided with specific structure, function and change, which was developed from geomorphic process changes and various interference. The stability and dynamic process of whole ecosystems through the research of landscape change with considering the time scale makes it understand. Therefore, the theory of landscape ecological must be a considering factor whether the land use planning or biodiversity conservation (Hobbs, 1997; Forman and Godron, 1986). Moreover, it is directivity on ecosystem changing, the way understands nature ecosystem changing mechanism through monitoring time series of landscape alteration (Antrop, 1998).

The afforestation project from 2002 promote by Forest Bureau, which estimate 3 forest parks, Danongdafu forest park in Hualien, Aogu wetland \& forest land in Chiayi and Linhousilin forest park in Pingtung to counseling and reward farmers for afforestation of agricultural land and developing a diversely forest ecosystem and habitat environment via ecological afforestation mode. The land use type was mainly planted Oryza sativa and Saccharum sinensis before the Linhousilin forest park was established, then turn cropland into the afforestation area since 2012. The ecosystem evolution and environmental habitat were formed by the landscape changing by years; so that, this study were concentrate on impact of landscape structure variety for species diversity, the variation of landscape process and its impact on the possibility of ecological corridors on Linhousilin and nearby mountain area.

\section{MATERIALS AND METHODS}

\subsection{Study area}

The Linhousilin forest park located across the Chaozhou, Wanluan and Shinpi townships of Pingtung County, adjacent Dunggang River in North and Linbian River in southeast. The forest park area is 1,005 ha. However, in this study, we disused the correlation of landscape pattern and low-elevation mountain ecosystem after the Linhousilin forest park was established in that the study area approximately expanding $11,391.48$ ha, e.g. Figure 1.

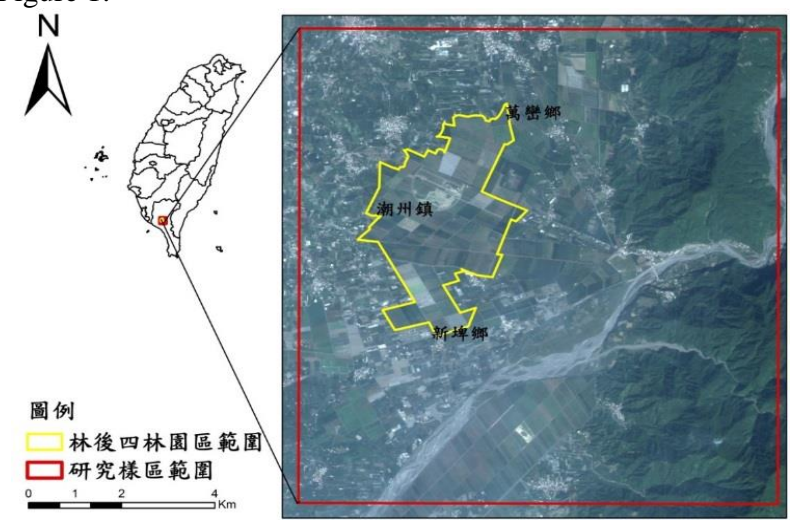

Figure1. Study area

\footnotetext{
* Corresponding author
} 


\subsection{Aerial photographs}

The aerial photographs in 2002, 2005, 2012 and 2014 were collected as material; the pixel size is $10 \mathrm{~cm} \times 10 \mathrm{~cm}$, which was suitable for creating the land cover condition of the study area. In addition to land use layer in Linhousilin forest park were drafted base on land use investigation in Taiwan.

\subsection{Land Use Analysis}

According to 2006 Intergovernmental Panel on Climate Change delimit the categories of land use as forest land, cropland, grassland, wetland, settlement, and other land (Table. 1). In order to ensure the accuracy of land cover spatial distribution, we collected the Coordinate position by GPS for checking the accuracy.

\section{Table 1. Definition of land use categories}

\begin{tabular}{|c|c|}
\hline land use categories & Definition \\
\hline Forest land & $\begin{array}{l}\text { The canopy ratio of plant is over10- } \\
30 \% \text {, and the height is least } 2-5 \mathrm{~m} \text {. }\end{array}$ \\
\hline Cropland & $\begin{array}{l}\text { Including tillage, farmland, and } \\
\text { agroforestry }\end{array}$ \\
\hline Grassland & Including pasture, grassland. \\
\hline Wetland & $\begin{array}{l}\text { The lands are cover by water for a } \\
\text { year, part of year or annual. }\end{array}$ \\
\hline Settlement & $\begin{array}{l}\text { Including all developed land. Road, } \\
\text { facility and buildings }\end{array}$ \\
\hline Other land & $\begin{array}{l}\text { Including bare, rocks and do not } \\
\text { belong to any of the above five } \\
\text { categories. }\end{array}$ \\
\hline
\end{tabular}

\subsection{Landscape Structure}

The landscape pattern structure analyzed by Fragstats 4.2 , the indices was selected as general area index, mean shape index, mean nearest neighbor distance, and Shannon's diversity index.

2.4.1 General area index: including number of patches (NP), patchiness density (PD), largest patch index (LPI), and mean patch size (MPS), e.g. Table 2.

Table 2. general area index formula

\begin{tabular}{|c|c|}
\hline general area index & formula \\
\hline $\mathrm{NP}$ & $\begin{array}{l}\mathrm{NP}=\mathrm{n}_{\mathrm{i}} \\
\text { Units: None. } \\
\text { Range: } \mathrm{NP}>1 \text {, without limit. } \\
\text { where } \quad \mathrm{n}_{\mathrm{i}}=\text { number of patches. }\end{array}$ \\
\hline PD & $\begin{array}{l}\mathrm{PD}=\frac{N}{A}(10000)(100) \\
\text { Units: None. } \\
\text { Range: } \mathrm{PD}>0, \text { limit by cell size. } \\
\text { where } \quad \mathrm{n}_{\mathrm{i}}=\text { number of patches. } \\
\quad \mathrm{A}=\text { total area of landscape. }\end{array}$ \\
\hline
\end{tabular}

\begin{tabular}{|c|c|}
\hline LPI & $\begin{array}{l}\text { LPI }=\frac{\max _{\mathrm{j}=1}^{\mathrm{n}}\left(\mathrm{a}_{\mathrm{ij}}\right)}{\mathrm{A}} \times 100 \\
\text { Units: Percent. } \\
\text { Range: } 0<\mathrm{LPI}<100 . \\
\text { where } \quad \mathrm{a}_{\mathrm{ij}}=\text { number of patches } \\
\quad \max \left(\mathrm{a}_{\mathrm{ij}}\right) \\
\quad \mathrm{A}=\text { total area of landscape }\end{array}$ \\
\hline MPS & $\begin{array}{l}\text { MPS }=\frac{A}{N} \times \frac{1}{10000} \\
\text { Units: } \mathrm{m}^{2} / \text { ha. } \\
\text { Range: } \mathrm{MPS}>0 . \\
\text { where } \quad \mathrm{A}=\text { area of patch } \\
\quad \mathrm{N}=\text { number of patches }\end{array}$ \\
\hline
\end{tabular}

2.4.2 Mean Shape Index (MSI): the variations of patch edge shape, when MSI $=1$ that mean the shape of patch close to smoothly.

$$
M S I=\frac{\sum_{j=1}^{n} \frac{p_{i j}}{\min \left(p_{i j}\right)}}{n_{i}}
$$

Units: None.

Range: $M S I \geqq 1$, without limit.

where $\quad \mathrm{p}_{\mathrm{ij}}=$ the perimeter of patch in particular type.

$\mathrm{n}_{\mathrm{i}}=$ number of patches.

$\min \left(\mathrm{p}_{\mathrm{ij}}\right)=$ the minimum area of patch in particular type.

\subsubsection{Mean Nearest Neighbor Distance (MNN):}

$$
M N N=\frac{\sum_{i=1}^{m} \sum_{j=1}^{n} h_{i j}}{N^{\prime}}
$$

Range: $M N N>0$

where $\quad h_{i j}=$ the distance between two patch type.

$N^{\prime}=$ number of patches.

2.4.4 Shannon's Diversity Index (SHDI): the diversity level of the landscape, when SHDI increase that mean multiple patches content in landscape.

$$
\mathrm{SHDI}=\sum_{i=1}^{m}\left(P_{i} \times \ln P_{i}\right)
$$

Units: None.

Range: SHDI $\geqq 1$, without limit.

where $\quad p_{i}=$ proportion of the landscape occupied by patch type.

\subsection{The potential of Ecological Corridors analysis}

\subsection{Least-Cost Path Method}

2.6.1 The costs of animal migration: The elements pattern of landscape, which has a resistance of interference when animal migration in that the land-use categories will be the interference elements. Besides, the target specie was selected Petaurista philippensis, which was based on the report of "Monitoring and Analysis of the Biotic Resources in Linhousilin Forest Park”. The factors affect the cost of animal migration were used Habitat suitability, Road density and Building density (Klar et al., 2012). 
We developed the figure of animal migration cost, the sum of weight ratio is $100 \%$, which habitat suitability is $45 \%$, road density is $25 \%$, and building density is $30 \%$.

2.6.2 Least-cost path method: The figures of animal migration cost in year 2002, 2005, 2012, and 2014 were developed. We discussed the potential of animal migration after the Linhousilin forest park built, the 4 starting points of path were set up on low-elevation mountain, and the 4 ending points of path were set up in the Linhousilin randomly for calculating least cost path of animal migration through the Cost Distance tool of ArcGIS 10.1.

2.6.3 Gravity model: The gravity model was used to measure the extent of interaction between habitats for determine the distinctiveness of ecological corridors. In general, if the interaction extent is stronger, it means provided with higher benefit of corridors between habitats (Kong et al., 2010; Uy and Nakagoshi, 2007).

$$
G_{a b}=\frac{N_{a} N_{b}}{D_{a b}^{2}}=\frac{\left[\frac{1}{P_{a}} \times \ln \left(S_{a}\right)\right]\left[\frac{1}{P_{b}} \times \ln \left(S_{b}\right)\right]}{\left(\frac{L_{a b}}{L_{\max }}\right)^{2}}=\frac{L_{\max }^{2} \ln \left(S_{a} S_{b}\right)}{L_{a b}^{2} P_{a} P_{b}}
$$

where $\quad \mathrm{G}_{\mathrm{ab}}=$ the interaction between node $\mathrm{a}$ and node $\mathrm{b}$.

$\mathrm{N}_{\mathrm{a}}$ : the weight value of node $\mathrm{a}$.

$\mathrm{N}_{\mathrm{b}}$ : the weight value of node $\mathrm{b}$.

$\mathrm{D}_{\mathrm{ab}}$ : the standard value of resistance between node $a$ and node $b$ corridors.

$\mathrm{P}_{\mathrm{a}}:$ the resistance value of node $\mathrm{a}$.

$\mathrm{P}_{\mathrm{b}}:$ the resistance value of node $\mathrm{b}$

$\mathrm{S}_{\mathrm{a}}:$ the area of node $\mathrm{a}$.

$\mathrm{S}_{\mathrm{b}}:$ the area of node $\mathrm{b}$.

$\mathrm{L}_{\mathrm{ab}}$ : the accumulation of resistance value between node $\mathrm{a}$ and node $\mathrm{b}$ corridors.

$\mathrm{L}_{\max }:$ the maximum value of resistance of total corridors.

\section{RESULTS}

\subsection{Land use categories changing}

This study developed the land cover layer of the Linhousilin forest park and in the vicinity of the park that the land use type concluded grassland, cropland, forest land, wetland, settlement and six other land use categories which defined by the IPCC.

3.1.1 Land use changing of Linhousilin forest park: Cropland and forest land are the main type of land use in the Linhousilin forest park. Particularly, cropland is the most of land use type in the year 2002 and 2005, e.g. Table 3, Figure 2.

Table 3. Statistics the land use of Linhousilin forest park.

\begin{tabular}{lrrrr|}
\hline & \multicolumn{1}{c}{2002} & \multicolumn{1}{c}{2005} & \multicolumn{1}{c}{2012} & \multicolumn{1}{c}{2014} \\
\cline { 2 - 5 } $\begin{array}{c}\text { land use } \\
\text { categories }\end{array}$ & area(ha) & area(ha) & area(ha) & area(ha) \\
\hline Forest land & 3.03 & 7.62 & 4.41 & 42.15 \\
Cropland & 947.49 & 943.94 & 163.24 & 123.69 \\
Grassland & 10.18 & 10.64 & 765.96 & 782.52 \\
Wetland & 8.31 & 8.95 & 7.39 & 8.94 \\
Settlement & 33.49 & 33.94 & 64.37 & 53.08 \\
Other land & 2.87 & 0.28 & 0 & 0.00 \\
\hline Total area & 1005.37 & 1005.37 & 1005.37 & 1005.37 \\
\hline
\end{tabular}

Figure 2. Land use changing during 2002-2014 in Linhousilin

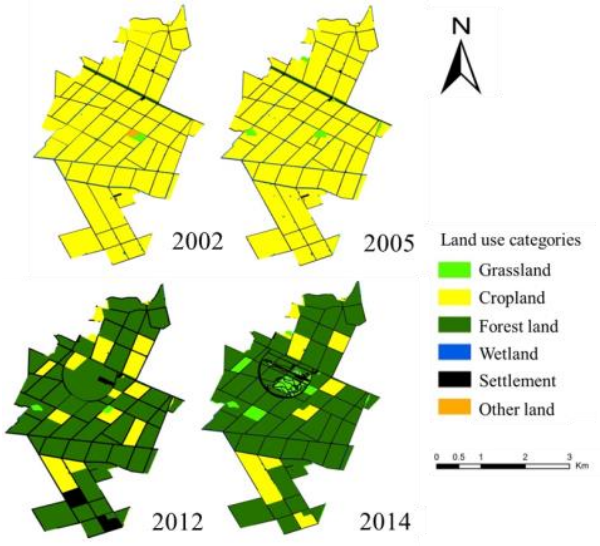

Furthermore, Council of Agriculture Forest Service translated plantation forest from cropland in afforestation project. At the same time, the roads were built surround central region in the Linhousilin forest park. The bare land in the year 2002 translated to afforestation land in 2012. Cropland and forest land are the largest area in land use type in the Linhousilin forest park and in the vicinity of the park; the area of grasslands and croplands is decreased in each period, conversely, the area of forest lands is increased significantly. Moreover, a number of roads were built at the central region of the Linhousilin forest park after 2014. At same time, landscape turf and ecological pool were built. e.g. Table 4, Figure 3.

Table 4. Statistics the land use of this study area.

\begin{tabular}{crrrr}
\hline & \multicolumn{1}{c}{2002} & \multicolumn{1}{c}{2005} & \multicolumn{1}{c}{2012} & \multicolumn{1}{c}{2014} \\
\cline { 2 - 5 } $\begin{array}{c}\text { land use } \\
\text { categories }\end{array}$ & aarea(ha) & aarea(ha) & aarea(ha) & aarea(ha) \\
\hline $\begin{array}{c}\text { Forest } \\
\text { land }\end{array}$ & 423.72 & 320.73 & 137.41 & 137.61 \\
Cropland & 6405.06 & 6440.78 & 4000.98 & 4002.08 \\
Grassland & 3136.86 & 3077.75 & 5634.67 & 5636.39 \\
Wetland & 495.28 & 472.82 & 602.71 & 603.76 \\
Settlement & 866.66 & 986.09 & 974.88 & 975.78 \\
Other land & 63.91 & 93.31 & 40.83 & 40.86 \\
\hline Total area & 11391.48 & 11391.48 & 11391.48 & 11391.48 \\
\hline
\end{tabular}

Figure 3. Land use changing during 2002-2014 in study area

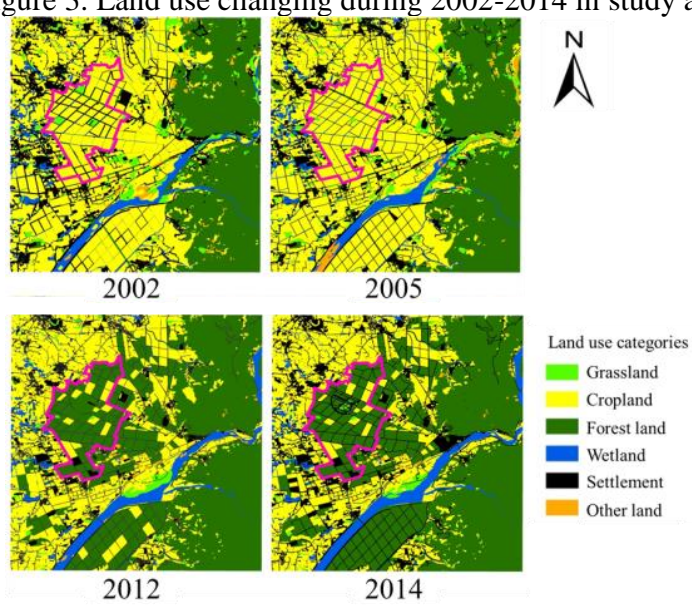




\subsection{The landscape structure changing}

NP of landscape structure in the Linhousilin forest park was decreased in the year 2012, and then it was increased in the year 2014 again. And the PD has the same trend with NP. Since the irrigation facilities which were increasing the quantity were constructed in the park. Therefore, the NP in the year 2005 is higher than 2002. The square patches of the section located in the central region were merged into a large area half-circle patch since it was constructed office buildings in 2012. The visible irrigation wells of section in the year 2005 were removed since the farmland translated to forest land. Thus, NP in the year 2012 is the lowest.The landscape index concluded that the NP of forest land where suitable for animal habitat increased gradually through the variation of landscape structure in the Linhousilin forest park and surrounding. Moreover, the MSI decreased, which presented the suitable habitats for animal were increased, e.g. Table 5.

Table 5. Statistics the landscape index of this study area.

\begin{tabular}{ccccc}
\hline Landscape Index & 2002 & 2005 & 2012 & 2014 \\
\hline NP & 2,890 & 2,983 & 3,551 & 3,668 \\
PD & 25,37 & 26.19 & 31.19 & 32.22 \\
LPI & 11.88 & 11.42 & 12.82 & 13.01 \\
MPS & 3.94 & 3.82 & 3.2 & 3.11 \\
MSI & 1.79 & 1.79 & 1.67 & 1.67 \\
SHDI & 1.16 & 1.16 & 1.16 & 1.15 \\
\hline
\end{tabular}

It could be found that the patch of forest land and the forest patch of low-elevation mountain ecosystem were contacted to be ecological corridors between low-elevation mountain ecosystem and the Linhousilin forest park after farmland translated to forest land through the land use layer of the Linhousilin forest park in 2005 to 2012. It could be expected that the diversity of the Linhousilin forest park could increase via ecological corridors formed, e.g. Figure 4.

Figure 4. The ecological corridors

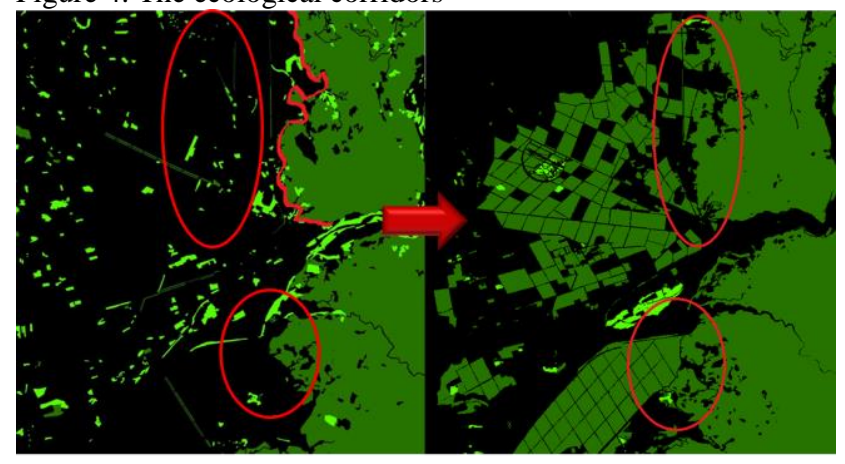

2005

2012

\subsection{The ecological corridors analysis}

Figure 5. showed that the boundaries forest stop on the east of Linhousilin of low elevation mountain, so that its shelter function were none-providing for animal migration. The leastcost path in 2002 and 2005 for animal migration from mountain area to Linhousilin, it must across the cropland and settlement which providing lower shielding function and increasing migration cost, only lack of grassland providing with stepping stone function. Overall, it is no obvious incentive and costly for animals in mountain areas which migrate to Linhousilin.

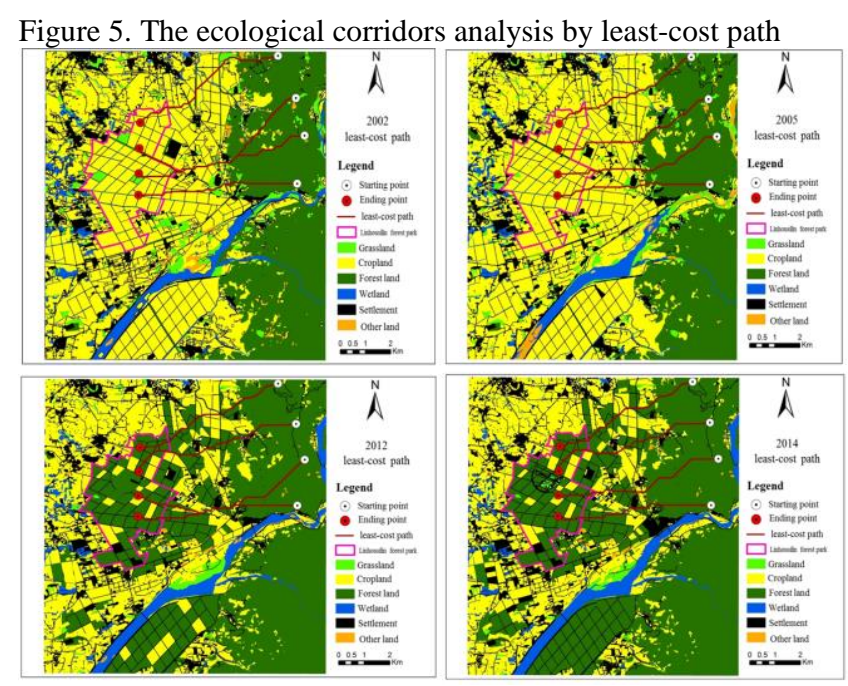

The Cropland turns into forest land on Linhousilin and its surround that makes the link between the afforestation area and the forest boundaries of low-elevation mountains, forest provides with the function of shelter and the resource higher than cropland and grassland so that the animals could select the path which has low migration cost and plant shelter.

The gravity value of least-cost path was calculated by the patch area of starting point and ending point, and cumulative resistance value, which obtain the extent of interaction between the habitat on starting point and the habitat on the ending point (Table 6). The high gravity value represents the corridor function of the path is significantly better, especially in the year 2012. Box-plot of gravity value in 4 periods, which indicated that the extent of interaction became stronger between the habitats of low-elevation mountain and the habitats of Linhousilin forest park, the variation in 2005 and 2012 was most significant, and the gravity value in the year 2012-2014 were higher significantly than year 2002-2005, e.g. Table 6 .

Table 6. Gravity value of least-cost path from 2002-2014.

\begin{tabular}{ccccc}
$\begin{array}{c}\text { Gravity value of } \\
\text { least-cost path }\end{array}$ & $\mathbf{2 0 0 2}$ & $\mathbf{2 0 0 5}$ & $\mathbf{2 0 1 2}$ & $\mathbf{2 0 1 4}$ \\
\hline Path 1 & 9.03 & 12.78 & 21.48 & 21.30 \\
Path 2 & 10.99 & 10.43 & 21.69 & 26.17 \\
Path 3 & 4.21 & 9.25 & 18.14 & 17.68 \\
Path 4 & 7.81 & 7.13 & 17.28 & 15.90
\end{tabular}

Figure 6. Box-plot for gravity value of least-cost path from 2002-2014. 


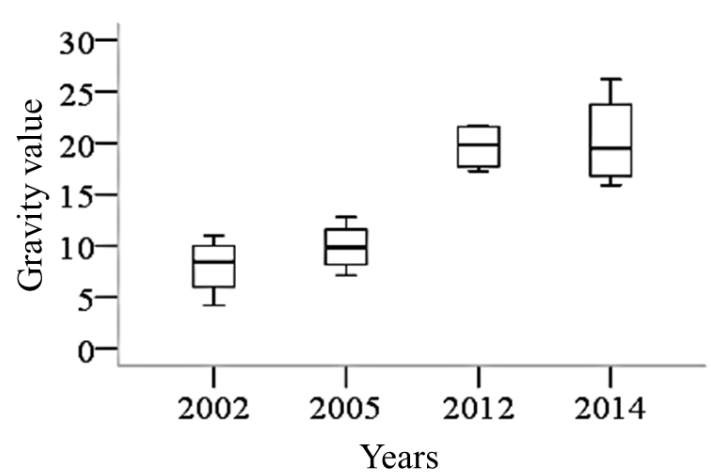

\section{CONCLUSIONS}

The aims to construct Linhousilin forest park in Pingtung are building a variable ecosystem, vegetation structure of lowelevation mountain and environmental habitat based upon the method of ecological afforestation. This study discusses variation of land use and landscape structure by change area of multitemporal land use type and contrasting of landscape indices. In order to understand the variation of connectivity between low-elevation mountain and Linhousilin forest park, this study use least-cost path method which is constructed by migration-cost method and its gravity value. Cropland and forest land is the largest area in land use type in Linhousilin forest park; the area of grasslands and farmlands is decreased in each period, conversely, the area of forest lands is increased significantly. The central of reason is both grasslands and croplands translated to forest lands in the year 2005 to 2012, the total area is $2,571.34 \mathrm{ha}$, it is about $22.57 \%$ of this study area.

In landscape structure, since croplands translated to forest lands in Linhousilin forest park, the ecological corridors are built by mosaics linking of low-elevation mountain and Linhousilin forest park. Least-cost path method could be calculated after using additive-cost figure which is overlaid by four periods land use figures, after that, the value could be calculated by each path gravity model. It could be detected the interaction of habitats between low-elevation mountain and Linhousilin forest park increase gradually by the variation of each year gravity values. Therefore, the function of ecological corridors increases gradually. By least-cost path method in the year 2012 and 2014, the forest boundaries of section afforestation land and lowelevation mountain ecosystem is connected after many croplands translated to forest lands in Linhousilin forest park and in the vicinity of the park. The animals expend lower cost to move into forest lands because forest provide with function of shelter and the resource higher than farmland and grassland. The incentive which the animal dwelling in the low-elevation mountain ecosystem migrate is increased because of providing habitat function such as shelter and resource by large area afforestation in Linhousilin forest park.

\section{REFERENCES}

Antrop, M., 1998 Landscape change: plan or chaos? Landscape and Urban Planning 41, pp. 155-161.

Forman, R. T. T., and M. Godron, 1986 Landscape Ecology, New York, John Wiley and Sons, pp. 619.
Hobbs, R., 1997 Future landscapes and the future of landscape ecology. Landscape and Urban Planning 37, pp. 1-9.

Klar, N., M. Herrmann, M. Henning-Hahn, B. Pott-Dörfer, H. Hofer, and S. Kramer-Schadt, 2012 Between ecological theory and planning practice:(Re-) Connecting forest patches for the wildcat in Lower Saxony. Germany. Landscape and Urban Planning 105(4), pp. 376-384.

Kong, F., H. Yin, N. Nakagoshi, and Y. Zong (2010) Urban green space network development for biodiversity conservation: Identification based on graph theory and gravity modeling. Landscape and Urban Planning 95, pp. 16-27.

Uy, P. D., and N. Nakagoshi, 2007 Analyzing urban green space pattern and eco-network in Hanoi, Vietnam. Landscape and Ecological Engineering 3(2), pp. 143-157.

Revised April 2016 